\title{
CONTROLE SOBRE PREÇOS: ANÁLISE DAS VARIÁVEIS E O PAPEL DA RESPONSABILIDADE SOCIAL NESSE CONTEXTO
}

\author{
Agessander Manoel, Lucas Rafael dos Santos \\ Universidade do Oeste Paulista - UNOESTE, Curso de Administração, Presidente Prudente/SP. E-mail: \\ agessandermanoel@hotmail.com
}

\begin{abstract}
RESUMO
Com o advento da globalização as empresas se viram obrigadas a inovar, traçando estratégia que possibilitem além de agradar o consumidor, maximizar a sua lucratividade. $O$ preço é um grande instrumento para tal, logo a formação de preços representa uma estratégia competitiva. Assim, o objetivo deste artigo é identificar em que circunstâncias as empresas são capazes de estabelecer seus próprios preços, qual(is) agente $(\mathrm{s})$ exerce $(\mathrm{m})$ controle sobre os preços e qual o papel da responsabilidade social neste contexto. Para tanto, far-se-á uso de uma pesquisa explicativa de cunho qualitativo, utilizando-se da pesquisa bibliográfica como instrumento de coleta de dados. Assim, pode-se constar que são muitas as variáveis que afetam o estabelecimento de preços, incluindo o mercado, as empresas, os consumidores, o governo e até mesmo o próprio sistema capitalista. Conclui-se que, as empresas necessitam traçar estratégias que possibilitem maior percepção de valor dos consumidores, para exercer maior controle sobre seus preços.

Palavras-chave: Consumidor. Lucratividade. Controle sobre preços. Responsabilidade Social. Valor.

\section{CONTROL OVER PRICES: ANALYSIS OF THE VARIABLES AND THE ROLE OF THE SOCIAL RESPONSIBILITY IN THIS CONTEXT}

\begin{abstract}
With the advent of globalization, companies are forced to innovate, tracing strategy that allow, in addition pleasing the consumer, maximizing profitability. The price is a great tool for this, so the pricing is a competitive strategy. The objective of this article is to identify the circumstances in which companies are able to set their own prices, which one $(\mathrm{s})$ agent $(\mathrm{s})$ carries $(\mathrm{m})$ control over prices and the role of social responsibility in this context. Therefore, far up it will use an explanatory research qualitative nature, using the literature as a data collection instrument. Thus, it can be noted that there are many variables that affect the pricing including market, companies, consumers, government and even the capitalist system itself. In conclusion, companies need to develop strategies that enable greater value perception of consumers to exercise greater control over their prices.
\end{abstract}

Keywords: Consumer. Profitability. Control over prices. Social Responsibility. Value. 


\section{INTRODUÇÃO}

Atualmente, as pessoas passaram a exigir mais das empresas, seja por produtos com qualidade superior e/ou diferenciados ou, até mesmo, por conscientização, optando por empresas socialmente, economicamente ou ambientalmente responsáveis para a satisfação de seus desejos e necessidades. Os desejos e necessidades evoluíram com a globalização, pois em decorrência do maior acesso a tecnologia e informação as barreiras se extinguiram. As empresas por sua vez se viram obrigadas a inovar e o que antes era sinônimo de vantagem competitiva (como por exemplo, a tecnologia), hoje apenas representa uma necessidade para manter-se vivo no mercado. Diante deste ambiente competitivo, as empresas necessitam traçar estratégias que possibilitem mais do que agradar o consumidor apenas, mas maximizar a sua lucratividade. 0 preço é um grande instrumento para tal, logo a formação de preços representa uma estratégia competitiva.

Para que uma empresa possa traçar suas estratégias de preço é necessária a identificação de variáveis que influenciam não somente os custos dessa ação, mas a viabilidade e aceitação deste preço pelo mercado consumidor. Não é mais possível utilizar a clássica formação de preço baseada única e exclusivamente na tríade custos fixos, custos variáveis e margem de contribuição. O consumidor ao avaliar a oferta estará avaliando seu custo e benefício e comparando com as demais ofertas de mercado, optando sempre pelo fornecedor que mais the ofereça vantagens para a aquisição. Variáveis como qualidade e posturas sustentáveis agregam valor ao produto e empresa despertando o interesse do consumidor.

Assim, o objetivo deste artigo é identificar em que circunstâncias as empresas são capazes de estabelecer seu próprio preço praticado, qual(is) o(s) agente(s) que realmente exerce $(\mathrm{m})$ controle sobre os preços e qual o papel da responsabilidade social neste contexto.

\section{METODOLOGIA}

Para Lakatos \& Marconi (1991, p. 155), “a pesquisa é um procedimento formal, com método de pensamento reflexivo, que requer um tratamento cientifico e se constitui no caminho para conhecer a realidade ou descobrir verdades parciais". Para o desenvolvimento desta discussão, optou-se pelo uso de uma pesquisa bibliográfica, que segundo Lakatos e Marconi (1991, p. 225) é a "A citação das principais conclusões a que outros chegaram permitir salientar a contribuição da pesquisa realizada, demonstrar contradições ou reafirmar comportamentos e atitudes". Isso permite uma discussão científica da realidade do tema proposto ao observar os vários aspectos históricos, conceituais e reflexivos apresentados pelos pesquisadores referenciados neste trabalho, apropriados ao tema escolhido para discussão.

\section{RESULTADOS}

Diante das características dos bens e serviços produzidos, as empresas são classificadas pela microeconomia de acordo com suas estruturas levando em consideração algumas características do mercado em que estão inseridas. Como exemplos dessas características de mercado, podem ser citados as características dos produtos, a existência ou não de barreiras a novos entrantes, o nível de concorrência entre as firmas, que afetam diretamente na decisão e comportamento de compra do consumidor e o controle de preços praticados. A competitividade entre as empresas, afeta diretamente a possibilidade de controle sobre os preços e, consecutivamente, a maximização do mark-up. Assim as estruturas de mercado menos competitivas permitem maior controle sobre os preços e maximização dos resultados (TEBCHIRANI, 2012). Com base nos estudos do autor, o quadro 1 apresenta as principais estruturas de mercado e suas principais características: 
Quadro 1 - Estrutura de mercado

\begin{tabular}{|l|l|l|l|l|}
\hline & $\begin{array}{l}\text { Concorrência } \\
\text { perfeita }\end{array}$ & $\begin{array}{l}\text { Concorrência } \\
\text { imperfeita }\end{array}$ & Oligopólio & Monopólio \\
\hline $\begin{array}{l}\text { Nível de } \\
\text { concorrência }\end{array}$ & Muito Grande & Grande & Pouca & Não há \\
\hline $\begin{array}{l}\text { Característica do } \\
\text { produto }\end{array}$ & Padronizado & Diferenciado & $\begin{array}{l}\text { Padronizado ou } \\
\text { diferenciado }\end{array}$ & Único \\
\hline $\begin{array}{l}\text { Barreiras à } \\
\text { entrantes }\end{array}$ & Não há & Não há & $\begin{array}{l}\text { Existem fortes } \\
\text { barreiras }\end{array}$ & $\begin{array}{l}\text { Existem fortes } \\
\text { barreiras }\end{array}$ \\
\hline $\begin{array}{l}\text { Controle sobre } \\
\text { preços }\end{array}$ & Nenhum & $\begin{array}{l}\text { Suave, face à } \\
\text { existência de vários } \\
\text { substitutos próximos }\end{array}$ & $\begin{array}{l}\text { Considerável, } \\
\text { principalmente se } \\
\text { houve cooperação } \\
\text { ou formação de } \\
\text { cartéis }\end{array}$ & Considerável(*) \\
\hline
\end{tabular}

(*) Sujeito à regulação

Fonte: Adaptação do autor com base em Tebchirani (2012, p. 71), Quadro 4.1 "Estruturas clássicas de mercado".

Desta forma é possível notar que o controle sobre o preço praticado está inter relacionado com o nível de concorrência entre as empresas que compõem o mercado em questão, a característica do produto (quanto a sua padronização, diferenciação ou exclusividade), à existência ou não de barreiras a novos concorrentes e a existência ou não de substitutos próximos ou a formação de cartéis. De modo geral, a microeconomia endossa o poder de controle sobre os preços a dois agentes: as empresas e o mercado, lembrando que em casos específicos há a presença de regulação do governo. Portanto o nível de controle das empresas sobre os preços depende de sua estrutura diante do mercado e quanto maior o nível de concorrência deste mercado, quanto maior homogeneidade dos produtos e inexistência de barreira a novos concorrentes, menor será o controle empresarial sobre os preços.

Kotler e Keller (2006) apresentam a evolução do produto no mercado através de uma ferramenta denominada Ciclo de Vida do Produto, onde a linha do tempo é dividida em: introdução, crescimento, maturidade e declínio. A cada estágio o produto terá que utilizar estratégias diferenciadas e exigirá esforços de marketing específicos, que passam pela analise de canais de distribuição, fornecedores, tecnologia, preço, comunicação, promoções, entre outros fatores, para que se mantenha o produto competitivo no mercado. Eles descrevem um padrão de comportamento comum nas vendas e lucratividade de produtos dentro destes estágios.

\section{DISCUSSÃO}

O preço percorre um dilema na sua formação que tange o mercado, as estruturas acadêmicas, os objetivos estratégicos e outros desafios na sua formação. Para entender este dilema é necessário compreender o capitalismo, que é um sistema econômico que engloba a produção, distribuição, oferta, demanda e preço. Arrighi (1996) desenvolveu um estudo profundo do capitalismo mostrando a inter-relação do nascimento da formação dos Estados nacionais e o capitalismo, apresentando seus ciclos de evolução no estudo da política e da economia mundial e dos aspectos correlacionados através da análise de três fatores da história do capitalismo: a hegemonia, o capitalismo e o territorialismo. Para Arrighi (1996) a hegemonia é a competência do Estado de exercer governo e liderança. O capitalismo refere-se a grupos capitalistas que detém o poder de mobilizarem os Estados de modo a permitirem maior atuação para suas empresas e respectivamente sua maior competitividade e por fim apresenta o territorialismo que é entendido 
como o controle dos recursos escassos através da expansão territorial, tornando-o um meio de acumulação de capital.

Arrighi (1996) afirma a tendência para a crise é indissociável a existência do próprio capitalismo. É um resultado da contradição entre o objetivo de acumulação capitalista (a valorização do capital e a apropriação da mais-valia de capital) e os meios pelos quais esse objetivo é exercido (crescimento da produtividade social e do desenvolvimento do caráter social da produção). A existência do capitalismo exerce influência no próprio sistema, além da produtividade e consumo, fatores estes estritamente relacionados à formação de preço, dentro da estrutura de governança.

A proposta do Ciclo de Vida do Produto, apresentada por Kotler e Keller (2006), coloca binômio preço-promoção como elementos de diferenciação que podem gerar quatro estratégias na fase de introdução do produto ao mercado. A primeira é conhecida como penetração rápida no mercado, que utiliza preços baixos e elementos de promocionais massivos principalmente no lançamento de produtos novos em um grande mercado (com maior sensibilidade a preços) e com grande possibilidade de concorrência, visando ganhos em escala. A segunda é a estratégia de penetração lenta no mercado, que utiliza preços baixos e poucos elementos promocionais por reconhecer no mercado um menor nível de concorrência. A terceira estratégia é denominada de skimming rápido e utiliza preços mais altos com alto nível elementos promocionais sendo indicada para um produto novo em uma nova categoria de produtos onde o consumidor deverá optar por pagar mais para obter um produto 'especial' e/ou ser o primeiro a tê-lo. A última é a estratégia de skimming lento, que é aplicada em um mercado onde o consumidor optará por pagar mais para obter um produto 'especial' e/ou ser o primeiro a tê-lo masque existe pouca concorrência, estabelecendo preços altos e com poucos elementos promocionais.

O estágio de crescimento é evidenciado pela queda do preço, pelo alto crescimento nas vendas e pela ampliação dos canais de distribuição. Nesta etapa há maior competitividade e oportunidade no mercado. O produto passa a sofrer alterações para prevalecer sobre a concorrência e manter o valor percebido pelo consumidor. No entanto o preço é reduzido em função da queda da margem de lucratividade, proporcionalmente ao volume vendido e a penetração e oferta dos concorrentes. Porém o lucro é compensado pelo volume vendido. Caso não apresente estratégias de diferenciação no produto a demanda tende a cair e exercer pressão sobre os preços.

$\mathrm{Na}$ fase de maturidade os preços e a lucratividade são levados ao menor patamar possível, reduzindo drasticamente a percepção de valor pelo cliente. $O$ desinteresse pelo produto marca a entrada na fase de declínio.

Outra variável que permite uma análise do controle de preços é apresentada na década de 70 por Porter (1986). Ele aborda a atratividade estrutural do mercado pelo que chama de cinco forças competitivas, que afetariam o ambiente organizacional através da análise do ambiente em que a organização está inserida e permitindo a definição de estratégias de melhor posicionamento no mercado.

Porter (1986) define que as cinco forças competitivas são: (a) Rivalidade entre os concorrentes; (b) Barreiras a novos entrantes; (c) Poder de barganha dos consumidores; (d) Poder de barganha dos fornecedores; (e) Ameaça de produtos substitutos. No que diz respeito à rivalidade entre os concorrentes, Blinder (2003) vincula que quanto maior o número de concorrentes ou seu nível de equilíbrio, maior será a intensidade da rivalidade entre si e menor percepção do valor dos produtos pelo consumidor, sendo a diferenciação de preço o caminho mais efetivo e rápido para ganhar a preferência do consumidor. Porter (1986) cita como principais fontes de ameaças a novos entrantes a economia de escala, diferenciação do produto, necessidade de capital, custos de mudança, acesso aos canais de distribuição e políticas governamentais entre outros fatores. Quanto maior a dificuldade de novos entrantes, maior será a 
facilidade de manutenção do preço estipulado em função da baixa concorrência de mercado. 0 poder de barganha dos consumidores refere-se a capacidade de pressão dos clientes para com as empresas principalmente nas questões de qualidade e preço do produto, assim quando ocorre esta situação, o preço passa a ser instrumento de barganha para fechamento de vendas. Sobre o poder de barganha de fornecedores, Blinder (2013) salienta que os fornecedores exercem seu poder com o objetivo de elevar os preços ou reduzir a qualidade do produto ofertado (diminuindo seus custos). Porter (1986) chama a atenção para a possibilidade dos produtos substitutos diminuírem os ganhos ou limitar a lucratividade da empresa.

A diferenciação de um produto consiste em torná-lo diferente (melhor) do que dos concorrentes, atribuindo-lhe qualidades perceptíveis ao consumidor, seja por suas características físicas ou não. De acordo com Tavares, Afonso e Locatelli (2011) existem três formas de diferenciação, sendo que a primeira refere-se a produtos com baixa padronização e com conceito de produto ampliado, incluindo serviços complementares. A segunda entende como o lançamento de produtos intrinsecamente diferentes em segmentos diferentes. Por último, busca-se gerar valor percebido, que não está intrinsecamente ligado ao produto em si, e sim à percepção do consumidor.

Kotler (2000) ressalta que o valor entregue ao cliente é que definirá o quanto o mesmo estará disposto a adquirir determinado produto e o quanto ele pagaria por isso. $O$ valor entregue ou cliente é entendido como a diferença entre o valor total para o cliente e o custo total para o cliente, ou seja, a ponderação dos benefícios percebidos pelo cliente, advindos da aquisição daquele bem ou serviços, em detrimento dos custos dispensados para adquiri-lo. Para Kotler (2000) um cliente está disposto a pagar mais por um produto dependendo do seu grau de satisfação.

Atualmente, os consumidores demonstram sensibilidade em relação a postura socialmente responsável das empresas. Neste contexto, a responsabilidade social corporativa vem ganhando importância e gerando um debate significativo nos meios acadêmico e empresarial (SERPA, 2006). De acordo com Serpa e Fourneau (2007) a postura de responsabilidade social passou a ser utilizada como fonte de vantagem competitiva.

Serpa (2006) destaca que a responsabilidade social representa um benefício na oferta para o consumidor, podendo este pagar cerca de $10 \%$ a mais por um produto, julgando-o como justo. Serpa e Fourneau (2007) completam, afirmando que a responsabilidade social exerce influência sobre a decisão de compra do consumidor. De acordo com Mota e Lima (2008) a mesma antecede a percepção de justiça de preço, gerando maior percepção de valor, satisfação e intenções de compra.

Para Serpa (2006), a responsabilidade social corporativa tem efeitos positivos na forma com que as pessoas avaliam as empresas e seus produtos, passando a agregar valor ao produto. Mota e Lima (2008) chamam a atenção ao progressivo aumento no nível de informações e o conhecimento sobre preço que o consumidor possui, influenciando no julgamento do preço em si (o quanto ele estaria disposto a pagar por algo) e no julgamento de como o preço foi estabelecido. Sendo o preço o responsável pela formação da percepção de valor e um indicativo do nível de qualidade de um produto.

\section{CONCLUSÃO}

Apesar da existência de muitos agentes que exercem influencias sobre o preço praticado (incluindo o mercado, o consumidor, o governo e até o próprio sistema capitalistas) as empresas possuem também o seu grau de controle. Isso porque, existem estratégias que possibilitam as organizações um maior controle sobre o preço através da agregação de valor aos seus produtos e à própria organização sob a percepção do consumidor e a própria sociedade. 
A postura sustentável nunca esteve tão em alta como nos dias atuais e a responsabilidade social é um dos pilares que compõem a sustentabilidade. As empresas socialmente responsáveis exercem maior impacto na sociedade no qual estão inseridas, sendo avaliadas positivamente pelos consumidores que por sua vez se dispõem a pagar mais por um produto que possui essa diferenciação.

A diferenciação é uma das estratégias mais eficiente no que diz respeito a valorização do produto diante do concorrente. Um produto com característica diferentes (e melhores) das encontradas no mercado possui maior aceitação, logo, também valor para o cliente e consecutiva predisposição para a aceitação de preços mais elevados.

Para finalizar, é importante mencionar que, diante a competitividade atual, o mercado não tem mais lugar para as empresas que optam por ganhos de escala. Baixo lucro individual e grandes projeções de venda deixaram de ser considerada uma estratégia inteligente de marketing. A melhor opção tornou-se valorizar o produto em si (e também a própria organização, no que diz respeito ao renome), para que a compra de seu produto não represente apenas uma simples aquisição, mais um grande investimento, que atenda às necessidades e desejos de seu adquirente.

\section{REFERÊNCIAS}

ARRIGHI, G. O longo século XX: dinheiro, poder e as origens de nosso tempo. São Paulo: UNESP/Contraponto. 1996.

BLINDER, M. Discussão do modelo porteriano através de críticas, teoria dos recursos e o caso Gol. 2003. 180 f. Dissertação (Mestrado em Administração de Empresas) - EAESP/FGV, São Paulo. 2003.

KOTLER, P. Administração de marketing: a edição do novo milênio. 10. ed. São Paulo: Prentice Hall, 2000.

KOTLER, P.; KELLER, K. L. Administração de marketing. 12. ed. São Paulo, Pearson, 2006.

LAKATOS, M.; MARCONI, M. A. Metodologia Científica. 2a․ ed. São Paulo: Atlas, 1991.

MOTA, M. O.; LIMA, R. C. Análise da Responsabilidade Social a luz da percepção de justiça de preço. EnANPAD 2008; XXXII Encontro da ANPAD; Rio de Janeiro - 6 a 10 de Setembro de 2008.

PORTER, M. Estratégia competitiva: Técnicas para a análise da indústria e da concorrência. 17. ed. Rio de Janeiro: Campus, 1986.

SERPA, D. A. F. Efeitos da Responsabilidade Social Corporativa na Percepção do Consumidor Sobre Preço e Valor: Um Estudo Experimental. Rio de Janeiro: UFRJ/COPPEAD, 2006. Tese (Doutorado em Ciência da Administração).

SERPA, D. A. F.; FOURNEAU, L. F. Responsabilidade Social Corporativa: uma investigação sobre a percepção do Consumidor. RAC, v. 11, n. 3, Jul./Set. 2007.

TAVAVES, M. C.; AFONSO, T.; LOCATELLI, R. L. Segmentação de mercado, diferenciação de produtos e a perspectiva da antropologia do consumo. Revista Gestão \& Tecnologia, Pedro Leopoldo, v. 11, n. 1, p. 106-122, jan./jun. 2011.

TEBCHIRANI, F. R. Princípios de economia: micro e macro. 1. ed. Curitiba: Intersaberes, 2012. 